\title{
Prevalence of malocclusion in Parsa district: A comparative study
}

\author{
Dr. Alok Kumar Jaiswal', Dr. Gunjan Kumar Shrestha², Dr. Wimby Tuladhar ${ }^{3}$, Dr. Binita Singh ${ }^{4}$, Dr. Rahul Gupta ${ }^{5}$ \\ ${ }^{1}$ Associate Professor, Department of Orthodontics and Dentofacial Orthopaedics, \\ 2,3,4,5 Assistant Professor, Department of Orthodontics and Dentofacial Orthopaedics, \\ M B Kedia Dental College and Teaching Hospital, Birgunj, Nepal \\ Corresponding author: Dr. Alok Kumar Jaiswal; Email: dralokjaiswal@gmail.com
}

\section{ABSTRACT}

Introduction: Malocclusion is one of the commonest problem in dentistry and the knowledge on its prevalence on particular population group is very important to plan oral health activities. The objective of this study is to assess the prevalence of malocclusion in school going children of Parsa district, Nepal, and to compare the same with previous study.

Materials and Method: The sample consisted of 250 males and 210 females (total of 460 subjects) aged between 6 to 17 years. Subjects without any previous orthodontic treatment and with no dental anomalies were included in this study. Census sampling was done for the patient visiting orthodontic from November 2018 to March 2019. Classification of malocclusion was based on Angle's classification of malocclusion. Collected data were entered in Microsoft Excel 2007 and converted into Statistical Package for Social Science (SPSS) Version 11.5 for statistical analysis. For descriptive statistics, percentage and proportion, were calculated, also tabular presentation were performed. For inferential statistics, Chi square test were used for intergroup comparison.

Result: School going children of Parsa district, Nepal suggests $50.47 \%$ female and $45.6 \%$ of male exhibits Angle's Class I malocclusion, $29.04 \%$ female and $30 \%$ male exhibits class II pattern, $11.4 \%$ female and $12.0 \%$ male exhibits class III pattern. The other findings reported in the study were, the occurrence of crowding of teeth more in males whereas the occurrence of spacing is more in females.

Conclusion: Majority of the subjects in the study had Class I malocclusion. Only $9.04 \%$ female and $12.4 \%$ of male showed normal class I occlusion. The occurrence of crowding of teeth more in males whereas the occurrence of spacing is more in females. This may be due to the incidence of missing tooth is more in females.

KEYWORDS: Class I, II, III, Malocclusion, Prevalence

\section{INTRODUCTION}

Oral health is a fundamental part of general health. WHO urges the implementation of national epidemiological studies to monitor the state of oral health in specific population groups ${ }^{1}$. To detect the malocclusion among children, the choice of population ranging from 6 to 11 years is important, because several children develop problems during this mixed dentition stage'.

Previous epidemiological studies carried out in different regions of Nepal indicate that the presence of malocclusion from the beginning of primary school age. ${ }^{2,3,4,5}$ Angle's classification of malocclusion in 1899 was an important step for the development of orthodontics ${ }^{6}$. It is not only subdivided the major types of malocclusion but also provided the first clear definition of normal occlusion. Angle's classification is based on the antero-posterior relationship of the jaws with each other and does not take into consideration of vertical or transverse discrepancies. Despite criticism by Hellman ${ }^{7}$ and Ackermann and profit ${ }^{8}$, Angle's classification has remained widely accepted and used in most of the dental institutions and clinical practitioners. Moyers ${ }^{9}$ considered it as the most practical and popular method of studying occlusion. Recently Grabber and Vanarsdall ${ }^{10}$ confirmed the simplicity of the system.

To date, no epidemiological study of malocclusion has been conducted in the Parsa region of Nepal. This study aimed to study the prevalence of malocclusion in the Parsa region as compared to other geographical region. The gender distribution of malocclusion and whether a 
significant difference exists among gender.

\section{MATERIALS AND METHOD}

The samples were selected from different schools of the Parsa as well as from OPD of Kedia Dental College, Birgunj, Nepal, in between the duration of November 2018 to March 2019. This study was conducted after getting ethical clearance from the institutional review board, $M$ B Kedia Dental College Birgunj, Nepal. Inform consent was obtained from parents as well as concerned school authorities before recording data. The total numbers of participants were 460 , out of which 250 males and 210 females were selected after the initial examination. The inclusion criteria for sample collection were subjects with fully erupted permanent first molars, with age less than 11 years and residents from the district of study site. However subjects with any serious illness, having cleft lip and palate and congenital malformations, any history of orthodontic treatment, trauma, or surgery were excluded from the study. Apart from that Migrated people from other districts and regions were excluded from the study.

Initial screening was done by a team to select the subjects. Assessment of malocclusion was done by using Angle's Classification and Dewey's modification. Final documentation was done by examination of each individual using mouth mirror and explorer. A portable headlamp was used in the schools while recording data for proper visibility. Final data were documented by the single examiner to avoid inter examination error. Findings like missing tooth, supernumerary tooth, spacing, crowding, increased overjet, deep bite, open bite, crossbite were recorded. The cross-sectional study was conducted among 460 subjects. The data were documented in excel sheets and analyzed. A comparison was made between male and female subjects and with other studies done in a different regions of Nepal.

\section{RESULT}

A total of 460 subjects were selected in the study, out of which 210 were females and 250 were males.

According Table 1 in Angle's Class I malocclusion $67.92 \%$ female and $71.92 \%$ male exhibited Dewey's modification type $1,20.75 \%$ female and $14.91 \%$ male exhibited Dewey's modification type 2, 6.60\% female and $4.0 \%$ male exhibited Dewey's modification type $3,2.83 \%$ female and $2.63 \%$ male exhibited Dewey's modification type $4,1.88 \%$ of female and $1.75 \%$ male exhibited Dewey's modification type 5 which were almost similar to the results obtained by sharma ${ }^{2}$. The above data suggests almost the same prevalence in Deeways modification type $3,4,5$ compared to females with males (table 1).

In Angle's class II malocclusion, 29.04\% female and $30 \%$ male exhibited class II pattern. Among the above, division 1 consisted of $78.68 \%$ female and $85.0 \%$ male whereas division 2 consisted of $21.31 \%$ of females and $14.66 \%$ male. The above data suggests that although there is an almost same prevalence of class II pattern in female and male subjects, division 1 pattern is higher in males whereas division 2 pattern is higher in females as reported in the previous study 4 .

In Angle's class III malocclusion, $11.4 \%$ female and $12.0 \%$ male exhibited class III pattern similar to the study done before by Piya et $\mathrm{al}^{3}$ but the prevalence is higher than other studies ${ }^{2,4,5}$. Among the above, 58.33\% female and $80.0 \%$ male exhibited Dewey's modification type $1,12.5 \%$ female, and $6.66 \%$ male exhibited Dewey's modification type $2,29.16 \%$ of female and $13.33 \%$ of male exhibited Dewey's modification type 3. Although there is an almost similar prevalence of class III pattern in female and male subjects, the prevalence of type 1 pattern was higher in males whereas type 3 pattern is higher in females (table 1).

Table 1: Pattern of Malocclusion and comparison with male and female

\begin{tabular}{|c|c|c|c|}
\hline Malocclusion & Male & Female & $P$ value \\
\hline $\begin{array}{l}\text { Class I normal } \\
\text { occlusion }\end{array}$ & 19(9.04\%) & $31(12.4 \%)$ & \multirow{5}{*}{0.611} \\
\hline $\begin{array}{l}\text { Class I } \\
\text { malocclusion } \\
\text { Type } 1 \\
\text { Type } 2 \\
\text { Type } 3 \\
\text { Type } 4 \\
\text { Type } 5 \\
\end{array}$ & $\begin{array}{l}106(50.47 \%) \\
72 \\
22 \\
7 \\
3 \\
2\end{array}$ & $\begin{array}{l}114(45.6 \%) \\
82 \\
17 \\
10 \\
3 \\
2\end{array}$ & \\
\hline $\begin{array}{l}\text { Class II } \\
\text { malocclusion } \\
\text { Division } 1 \\
\text { Division } 2 \\
\end{array}$ & \begin{tabular}{|l|}
$61(29.04 \%)$ \\
48 \\
13
\end{tabular} & $\begin{array}{l}75(30.0 \%) \\
64 \\
11\end{array}$ & \\
\hline $\begin{array}{l}\text { Class III } \\
\text { malocclusion } \\
\text { Type } 1 \\
\text { Type } 2 \\
\text { Type } 3 \\
\end{array}$ & $\begin{array}{l}24(11.4 \%) \\
14 \\
3 \\
7\end{array}$ & $\begin{array}{l}30(12.0 \%) \\
24 \\
2 \\
4\end{array}$ & \\
\hline Total & 210 & 250 & \\
\hline
\end{tabular}


The other noticeable findings reported in the study were, the occurrence of crowding of teeth more in males whereas the occurrence of spacing is more in females, maybe due to the incidence of a missing tooth is more in females as noticed before by Baral ${ }^{4}$ (table 2). Chisquare test was performed to compare the male and female with the prevalence of the malocclusion. There were no significant difference between Male and female $(p=0.611)$ in regards to the presence of malocclusion.

Table 2: Other malocclusion traits

\begin{tabular}{|l|l|l|}
\hline Other Findings & Male & Female \\
\hline Increased overjet & 90 & 112 \\
\hline Deep bite & 84 & 95 \\
\hline Anterior cross bite & 7 & 4 \\
\hline Posterior crossbite & 2 & 3 \\
\hline Open bite & 5 & 3 \\
\hline Crowding upper arch & 127 & 130 \\
\hline Crowding lower arch & 109 & 121 \\
\hline Spacing upper arch & 59 & 87 \\
\hline Spacing lower arch & 48 & 83 \\
\hline Missing tooth & 13 & 22 \\
\hline Supernumarary teeth & 5 & 3 \\
\hline Scissorbite & 3 & 2 \\
\hline
\end{tabular}

\section{DISCUSSION}

The present study was designed to provide information about the prevalence of malocclusion among 6 to 17 years of school-going children of Parsa district and compare the data with other studies that were done in different regions of Nepal. When findings were compared with similar studies done in a different zone of Nepal, the occurrence of Class I normal occlusion is almost the similar as the study done before by Singh et $\mathrm{al} \mathrm{l}^{5}$.

Whereas, for Angle's Class I malocclusion our findings are similar with those obtained by Singh et $\mathrm{al}^{5}$, but lower then others ${ }^{2,3,4}$. This variation may be due to no segregation of males and females in the studies done before. Similarly, for Angle Class II malocclusion our findings are further in concordance with the results obtained by Sharma ${ }^{2}$, Baral ${ }^{4}$, Singh $^{5}$ but higher to studies done by Piya et $\mathrm{al}^{3}$.
Similarly, for angle class III malocclusion our findings are nearly similar to the results obtained by Sharma ${ }^{2}$ and Piya et $\mathrm{al}^{3}$, but higher to studies done by $\mathrm{Baral}^{4}$

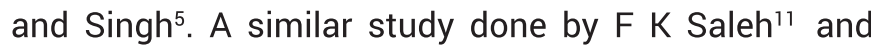
compared with other ethnic groups found significant changes compared to different populations. The prevalence of malocclusion may vary even among the population having the same origin ${ }^{12,13}$. This study showed that prevalence of crowding of teeth was more in males whereas the occurrence of spacing is more in females may be due to the incidence of the missing tooth is more in females as found in the previous study $^{4}$. These findings suggest that there are a large number of Nepalese subjects presenting with mild to severe orthodontic problems as reported by others ${ }^{2,3,4,5}$. A similar finding was recorded for Kuwaitis ${ }^{15}$, Turkey ${ }^{16}$, and Qingtao ${ }^{17}$ populations.

\section{CONCLUSION}

Our findings of school-going children of Parsa district, Nepal suggests Only $9.04 \%$ female and $12.4 \%$ of male showed normal class I occlusion and of the remaining subjects, $50.47 \%$ female and $45.6 \%$ of male exhibited Angle class I malocclusion, $29.04 \%$ female and $30 \%$ male exhibited class II pattern, $11.4 \%$ female and $12.0 \%$ male exhibited class III pattern. Proffit et al ${ }^{14}$ presented the data from the Third National Health and Nutrition Examination Survey, (NHANES III survey) and reported that $30 \%$ had Angle's class I normal occlusion, $50 \%$ had Class I malocclusion, 15\% had Class II malocclusion and $1 \%$ had Class III malocclusion. The difference in sample size, ethnic variation, and socio-demographic variations could be the reason for the difference with other studies and within the Nepalese population.

\section{LIMITATIONS}

The study was done with a smaller sample size so further studies based on a larger sample size, are required to confirm the results of the present study. Further study is required to compare the study done in a male group compare to the female group of Nepalese population having different types of Angle's malocclusion.

\section{OJN}




\section{REFERENCES}

1. Cirulli N, Cantore S, Ballini A, Perillo L, Giannico OV, Tafuri S, et al. Prevalence of caries and dental malocclusions in the apulian paediatric population: an epidemiological study. Eur J Paediatr Dent. 2019 Jun;20(2):100-4.

2. Sharma JN. Pattern of distribution of malocclusions in patients seeking orthodontic treatment at BPKIHS from Sunsari District of Nepal. Health Renaiss. 2010 May-Aug;8(2):93-6.

3. Piya A, Shrestha VB, Acharya J, Khanal S, Bhattarai P. Pattern of Distribution of Malocclusion among Patients Seeking Orthodontic Treatment at Dental College- Nepal Medical College. Journal of Nepal Dental Association. 2013 Jul-Dec;13(2):36-40.

4. Baral P. Prevalence of Malocclusion in Western Nepal. Orthodontic Journal of Nepal. 2015 Dec;5(2):6-8.

5. Singh VP, Sharma A. Epidemiology of Malocclusion and Assessment of Orthodontic Treatment Need for Nepalese Children: Hindawi Publishing Corporation International Scholarly Research Notices Volume 2014, Article ID 768357: 2-4

6. Balaji S.I. Orthodontics the art and science. 3rd ed. March 2005: 55-56.

7. Hellman M. Variation in occlusion. Dent Cosmos. 1921;63:608-17.

8. Ackerman JL, Proffit WR. The characteristics of malocclusion: a modern approach to classification and diagnosis. Am J Orthod. 1969 Nov;56(5):443-54.

9. Moyers RE. Handbook of Orthodontics. 4th ed. Chicago: Yearbook Medical Publishers; 1988. pp. 235-40.

10. Graber TM, Vanarsdall RL. Orthodontics, current principles, and techniques. St. Louis: CV Mosby Company; 1994.

11. Saleh FK. Prevalence of malocclusion in a sample of Lebanese schoolchildren: an epidemiological study. East Mediterr Health J. 1999 Mar;5(2):337-43.

12. Aniket H. Vibhute, Nupura A. Vibhute, RajendraDaule, Prevalence of malocclusion characteristic, and chief motivational factors for treatment in orthodontic patients from Maharashtra, India. J Orthop Res. 2013 May-Aug;1 (2):62-5.

13. Sayin MO, Türkkahraman H. Malocclusion and crowding in an orthodontically referred Turkish population. Angle Orthod. 2004 Oct; 74(5):635-9.

14. Proffit WR, Fields HW Jr, Moray LJ. Prevalence of malocclusion and orthodontic treatment need in the United States: estimates from the NHANES III survey. Int J Adult Orthodon Orthognath Surg. 1998;13(2):97-106.

15. Behbehani F, Årtun J, Al-Jame B, Kerosuo H. FarajBehbehani, Jon Årtun, Badreia Al-Jame, Heidi Kerosuo. Prevalence and Severity of Malocclusion in Adolescent Kuwaitis. Med Princ Pract. 2005;14(6):390-5.

16. Celikoglu M, Akpinar S, Yavuz I. The pattern of malocclusion in a sample of orthodontic patients from Turkey. Med Oral Patol Oral Cir Bucal. 2010. Sep 1;15 (5):e791-6 https://doi.org/10.4317/medoral.15.e791.

17. Yang J, Li YZ, Liu Y, Zhang Q, Yuan X. [Epidemiological survey of malocclusion in 8-9 year-old children in Qingdao Laoshan district]. Shanghai Kou Qiang Yi Xue. 2019 Jun;28(3):284-7.

18. Zou J, Meng M, Law CS, Rao Y, Zhou X. Common dental diseases in children and malocclusion. Int J Oral Sci. 2018 Mar;10(1):7. 